\title{
Secondary pneumomediastinum and bilateral tension pneumothorax following aneurysmal subarachnoid hemorrhage surgery: a report of five cases
}

Haichun Ma ( $\square$ mahc@jlu.edu.cn )

Jilin University First Hospital https://orcid.org/0000-0002-2949-3342

Chengluan Xuan

Jilin University First Hospital

Kan $\mathrm{He}$

Jilin University First Hospital

Dan Wang

Jilin University First Hospital

Qunshu Zhang

National Institutes of Health

\section{Case Report}

Keywords: Secondary pneumomediastinum; Bilateral tension pneumothorax; Aneurysmal subarachnoid hemorrhage

Posted Date: January 8th, 2019

DOI: https://doi.org/10.21203/rs.2.180/v1

License: (c) (i) This work is licensed under a Creative Commons Attribution 4.0 International License.

Read Full License 


\section{Abstract}

Background: Simultaneous occurrence of secondary pneumomediastinum and bilateral tension pneumothorax is an uncommon complication of aneurysmal subarachnoid hemorrhage.

Case presentation: In the present study, all five patients were admitted with Hunt and Hess grade IV. Pneumomediastinum and bilateral tension pneumothorax occurred simultaneously after clipping or embolization. Tube thoracostomy and underwater sealed drainage were performed to improve oxygen saturation and hemodynamics. Of five patients, one was decided to cease treatment on the first day after surgery, three patients achieved good recovery, and one patient suffered serious disability.

Conclusions: Anesthesiologists should be aware of pneumomediastinum and bilateral tension pneumothorax occurring after surgical or neurointerventional treatment in subarachnoid hemorrhage patients with poor Hunt and Hess grade. Timely diagnosis and chest tube insertion were extremely crucial in the treatment of these patients.

Keywords: Secondary pneumomediastinum; Bilateral tension pneumothorax; Aneurysmal subarachnoid hemorrhage

\section{Introduction}

Aneurysmal subarachnoid hemorrhage (aSAH) is not a lethal condition but it can be considered a lifethreatening disease if not properly treated. In addition to intracranial bleeding, aSAH can also affect other organ systems and cause cardiac arrhythmia, pneumonia, neurogenic pulmonary edema, acute lung injury (ALI), and acute respiratory distress syndrome $(1,2)$. Secondary pneumomediastinum and bilateral tension pneumothorax occurring simultaneously after aSAH surgery is a rare event and has not been reported. Pulmonary involvements can lead to pneumomediastinum, including excessive coughing induced by asthma or respiratory infection, intestinal lung disease, excessive vomiting, lung malignancy, and trauma $(3,4)$. In this case series, we describe five cases of simultaneous secondary pneumomediastinum and bilateral tension pneumothorax in five aSAH patients during the respiratory recovery stage with an inserted tracheal tube after surgery. These pulmonary complicationspneumomediastinum and tension pneumothorax-have never been reported.

\section{Case Presentation}

From December 2016 to January 2018, our hospital admitted 5 patients with acute aSAH who developed secondary pneumomediastinum and bilateral tension pneumothorax during the respiratory recovery stage with tracheal tube insertion after aneurysm clipping or embolization surgery. The characteristics of these 5 patients are shown in Table 1. The patients are numbered by admission time. Among the five patients aneurysm location were distributed as follows: two in the right middle cerebrum, one in the left internal carotid artery-posterior communicating artery, one in the left middle cerebral artery, and one in the communicating artery. All five patients were Hunt and Hess grade IV. Patient one presented pulmonary 
edema, and the other four patients showed pneumonia on chest digital radiograph (DR) or computed tomography (CT) prior to the surgery (Figure 1). These patients were not screened for any other pulmonary parenchyma alteration. Anesthesia was induced with fentanyl and propofol, and tracheal intubation was facilitated with atracurium. Anesthesia was maintained using propofol and remifentanil infusion. Of five patients, four underwent clipping and one underwent embolization. During weaned from mechanical ventilation after surgery, those patients were kept under sedation with remifentanil to avoid coughing and prevent hypertensive crisis. Because of unconsciousness before surgery, the five patients were not extubated after surgery, despite recovery of spontaneous breathing. Five patients developed pneumomediastinum and bilateral tension pneumothorax at different times: $180 \mathrm{~min}, 40 \mathrm{~min}, 45 \mathrm{~min}, 99$ min, and 60 min after recovery of spontaneous breathing, and different sites: three in the intensive care unit and two in the operating room (Table 1). Chest CT or DR was performed before or after chest tube thoracostomy (Figure 2). After abnormal respiration developed, immediate life-threatening conditions presented in all five patients, and two patients required cardiopulmonary resuscitation, which indicated that pneumomediastinum and tension pneumothorax could be a severe complication following aSAH surgery. The common signs of five patients were low saturation and decreased oxygen compliance presenting with hemodynamic instability. After tube thoracostomy and underwater sealed drainage were performed, hemodynamics was significantly improved. Of five patients, patient three was decided to cease treatment on the first day after surgery, patient one suffered serious disability, and other three patients achieved good recovery. During the follow-up visits 8 months after the hospital discharge, all four patients were alive and had no pulmonary complications.

\section{Discussion}

Pneumomediastinum is a rare situation in which air is present in the mediastinum. Depending on the pathophysiology of pneumomediastinum, it is usually described as spontaneous and secondary. Spontaneous pneumomediastinum is the presence of air into the mediastinum without any obvious causative factor. The secondary pneumomediastinum may be induced by mechanical ventilation, thoracic trauma, and some invasive procedures. In this report, although the pneumomediastinum and bilateral tension pneumothorax occurred secondary to intubation and mechanical ventilation, the airway had no observable injury as viewed by bronchoscopy. The pathophysiology of these five cases could also be explained as spontaneous pneumomediastinum.

As reported, the pathophysiology of spontaneous pneumomediastinum is based on alveolar rupture due to a rapid increase of intrathoracic pressure, followed by air tracks through the pulmonary interstitium along the bronchovascular sheaths toward the pulmonary hila into the mediastinum, called the Macklin effect $(5,6)$. Because different amounts of time had elapsed between the chest CT scans and development of pneumomediastinum and tension pneumothorax, the air of bronchovascular sheaths removed by chest tube insertion, only the patient 2 and patient 5 exhibited the Macklin effect in CT image (Figure 3). Many conditions have been reported to be associated with pneumomediastinum, such as bronchial asthma, diabetic ketoacidosis, severe cough or vomiting, and other activities associated with the Valsalva maneuver (6). From the time of development, all the pneumomediastinum and 
pneumothorax occurred during the stage of recovery of spontaneous breathing shortly after the completion of surgery. Although the remifentanil was administrated continuously to avoid coughing, irregular respiratory rate and tidal volume might also be the causative factors of alveolar rupture.

In one patient, severe neurogenic pulmonary edema was detected before surgery, and the other four patients also presented varying degrees of pneumonia. All five patients were admitted with grade IV. One study found that pulmonary edema was unobserved in patients with grade I- III, and pulmonary edema appeared explicitly in grade IV or V patients with a prevalence of $31.3 \%$ (7). Another study found poorgrade subarachnoid hemorrhage to be an independent predictor of ALI and acute respiratory distress syndrome (8). For our five cases, the ALI during aSAH might be etiological basis of pneumomediastinum and bilateral tension pneumothorax.

The decision of whether to extubate the trachea at the end of the surgical procedure usually depends on the severity of aSAH, preexisting illness, and the preoperative level of consciousness. We consider that a shorter time period between chest CT scan and surgery could allow more accurate assessment of acute lung injury complicated from aSAH. The respiratory condition should also be checked immediately after surgery to re-evaluate the pulmonary condition in case there is an immediate need for management. If the patient had ALI either before or after surgery, paralysis and sedation should be performed until the lung injury improves.

\section{Conclusion}

ALI induced by poor-grade aSAH is part of the etiology of pneumomediastinum and bilateral tension pneumothorax. Anesthesiologists should be aware of and cautious about these life-threatening complications in poor-grade aSAH. Delayed spontaneous respiratory recovery, prolonged paralysis and sedation might decrease the risk for pneumomediastinum and pneumothorax. Finally, timely diagnosis as well as tube thoracostomy and underwater sealed drainage is extremely crucial to treating these patients.

\section{Abbreviations}

Aneurysmal subarachnoid hemorrhage, aSAH; acute lung injury, ALI; digital radiograph, DR; computed tomography, CT.

\section{Declarations}

Ethics approval and consent to participate

Not applicable

Consent publication 
Informed consent was obtained from the patients or their healthcare proxies to publish their health information and related imaging.

Availability of data and material

We declared that materials described in the manuscript, including all relevant raw data, will be freely available to any scientist visiting to use them for non-commercial purposes, without breaching participant confidentiality.

Conflict of interest

The authors declared that they have no competing interests.

\section{Funding}

This study was supported by Program of the National Natural Science Foundation of China (No.81800006).

Authors' contributions

CLX carried out the data collection and drafted the initial manuscript. KH and DW carried out the literature search, prepared and reviewed the manuscript. QSZ reviewed and revised the manuscript. HCM critically reviewed the manuscript. All authors read and approved the final manuscript.

Acknowledgements

No

\section{References}

1. Peterson E, Heros RC. Don't lose the lungs for the brain: pulmonary complications after subarachnoid hemorrhage. World Neurosurg. 2014;82: er67-er68.

2. Solenski NJ, Haley EC, Kassell NF,Kongable G, Germanson T, Trukowski L, et al. Medical complications of aneurysmal subarachnoid hemorrhage: a report of the multicenter, cooperative aneurysm study. Participants of the Multicenter cooperative aneurysm study. Crit Care Med. 1995;23:1007-1017.

3. Caceres M, Ali SZ, Braud R, et al. Spontaneous pneumomediastinum: a comparative study and review of the literature. Ann Thorac Surg 2008;86:962-6.

4. Russo A, Del Vecchio C, Zaottini A, et al. Role of emergency thoracic ultrasonography in spontaneous pneumomediastinum. Two Case report. G Chir 2012;33:285-96.

5. Sakai M, Murayama S, Gibo M, Akamine T, Nagata O. Frequent cause of the Macklin effect in spontaneous pneumomediastinum: demonstration by multidetector-row computed tomography. $J$ Comput Assist Tomogr. 2006;30:92-4. 
6. S.Murayama, S.Gibo. Spontaneous pneumomediastinum and Macklin effect: Overview and appearance on computed tomography. World J Radiol 2014 Nov 28;6(11):850-854.

7. Saracen A, Kotwica Z, Wozniak-Kosek A, Kasprzak P. Neurogenic pulmonary edema in aneurysmal subarachnoid hemorrhage. Adv Exp Med Biol. 2016;952:35-39.

8. Kahn JM, Caldwell EC, Deem S, Newell DW, Heckbert SR, Rubenfeld GD: Acute lung injury in patients with subarachnoid hemorrhage: incidence, risk factor, and outcome. Crit Care Med. 2006;34:196-202.

\section{Tables}

\section{Table 1 Summary of cases}

\begin{tabular}{|c|c|c|c|c|c|}
\hline Patient & 1 & 2 & 3 & 4 & 5 \\
\hline Sex & Female & Male & Female & Female & Male \\
\hline Age (y) & 45 & 66 & 59 & 46 & 46 \\
\hline Smoking history & No & Yes & No & No & No \\
\hline Prior comorbidity & COPD & $\begin{array}{l}\text { Diabetes } \\
\text { Hypertension } \\
\end{array}$ & Hypertension & None & None \\
\hline $\begin{array}{l}\text { Bleeding components in primary } \\
\text { head CT }\end{array}$ & $\begin{array}{l}\text { Ventricle, right } \\
\text { temporal lobe, } \\
\text { subarachnoid }\end{array}$ & Subarachnoid & $\begin{array}{l}\text { Subarachnoid, } \\
\text { right temporal } \\
\text { lobe }\end{array}$ & Subarachnoid & $\begin{array}{l}\text { Subarachnoid, } \\
\text { left temporal } \\
\text { lobe }\end{array}$ \\
\hline Aneurysm location & Right MCA & Left IC-PC & Right MCA & ACA & Left MCA \\
\hline Surgical procedure & Clipping & Clipping & Clipping & Embolization & Clipping \\
\hline Ventilation mode & $\mathrm{VC}(8 \mathrm{~mL} / \mathrm{kg})$ & $\mathrm{VC}(8 \mathrm{~mL} / \mathrm{kg})$ & $\mathrm{VC}(8 \mathrm{~mL} / \mathrm{kg})$ & $\mathrm{VC}(8 \mathrm{~mL} / \mathrm{kg})$ & $\mathrm{VC}(8 \mathrm{~mL} / \mathrm{kg})$ \\
\hline $\begin{array}{l}\text { Pneumomedisastinum occurrence } \\
\text { time/location (after spontaneous } \\
\text { breathing recovered) }\end{array}$ & $180 \mathrm{~min} / \mathrm{ICU}$ & $\begin{array}{l}40 \\
\text { min/operation } \\
\text { room }\end{array}$ & $\begin{array}{l}45 \\
\text { min/operation } \\
\text { room }\end{array}$ & $99 \mathrm{~min} / \mathrm{ICU}$ & $60 \mathrm{~min} / \mathrm{ICU}$ \\
\hline CPR perform & Yes & No & Yes & No & No \\
\hline Tube thoracostomy & Bilateral & Left & Bilateral & Bilateral & Bilateral \\
\hline Clinical outcome & Serious disabled & $\begin{array}{l}\text { Good } \\
\text { recovery }\end{array}$ & $\begin{array}{l}\text { Abandon } \\
\text { treatment }\end{array}$ & $\begin{array}{l}\text { Good } \\
\text { recovery }\end{array}$ & Good recovery \\
\hline
\end{tabular}

Abbreviations: COPD, chronic obstructive pulmonary disease; CT, computed tomography; MCA, middle cerebral artery; IC-PC, internal carotid artery; ACA, anterior cerebral artery; VC, volume control; ICU, intensive care unit; CPR, cardiopulmonary resuscitation.

\section{Figures}


Figure 1
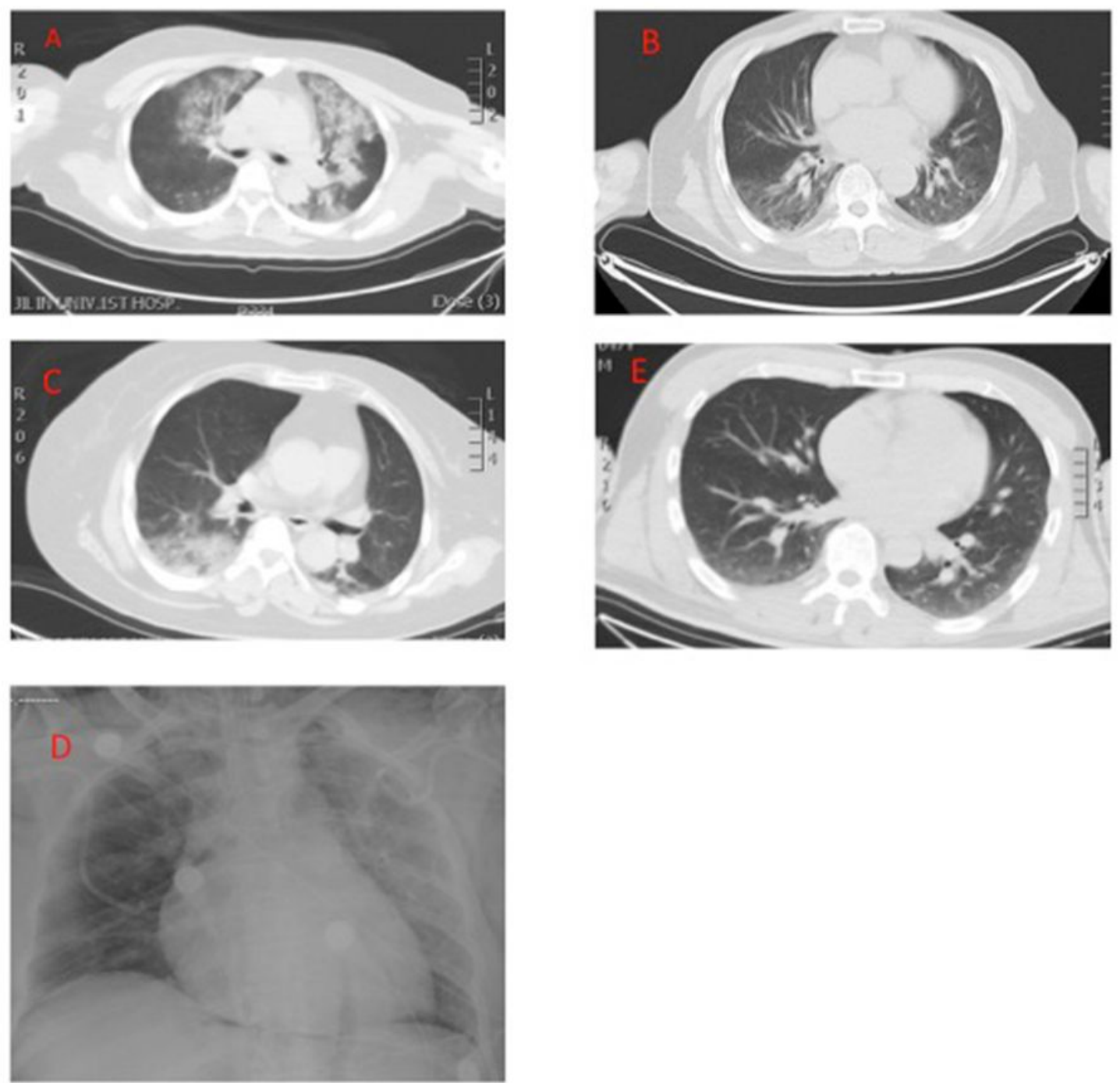

\section{Figure 1}

Chest DR or CT scanning before surgery. A, B, C, D, and E are patient 1 , patient 2 , patient 3 , patient 4 , and patient 5 , respectively. Patient 1 presented pulmonary edema, and the other four patients showed different degrees of pneumonia. 
Figure 2
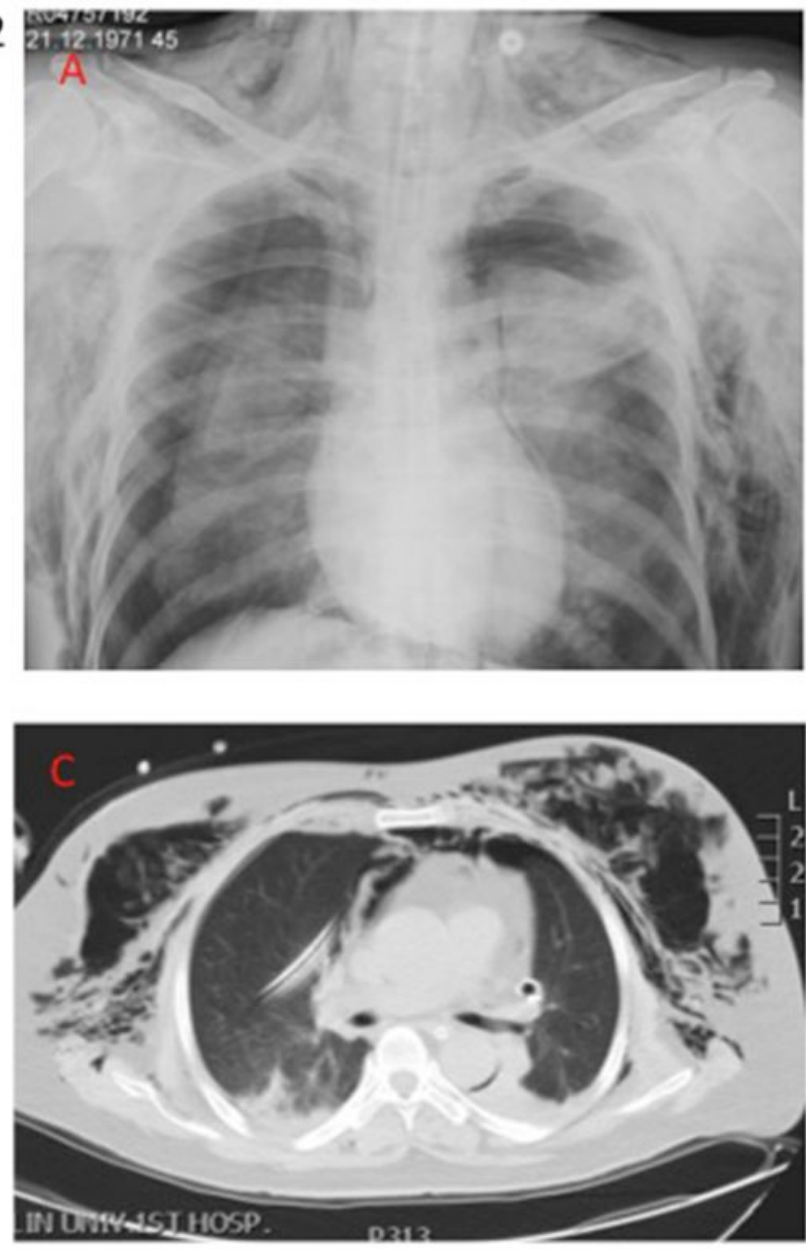
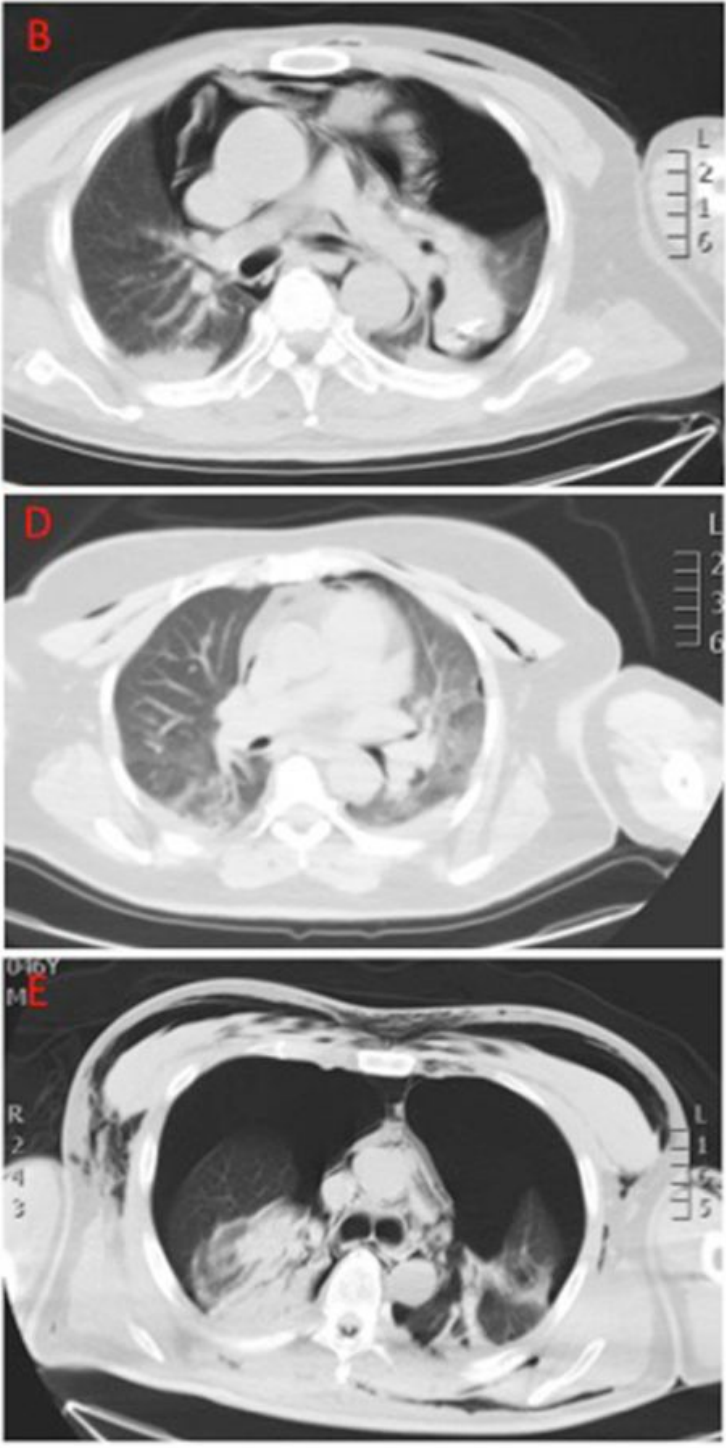

Figure 2

Chest DR or CT scanning before or after chest tube insertion. A, B, C, D, and E are patient 1, patient 2, patient 3 , patient 4 , and patient 5 , respectively. 
Figure 3
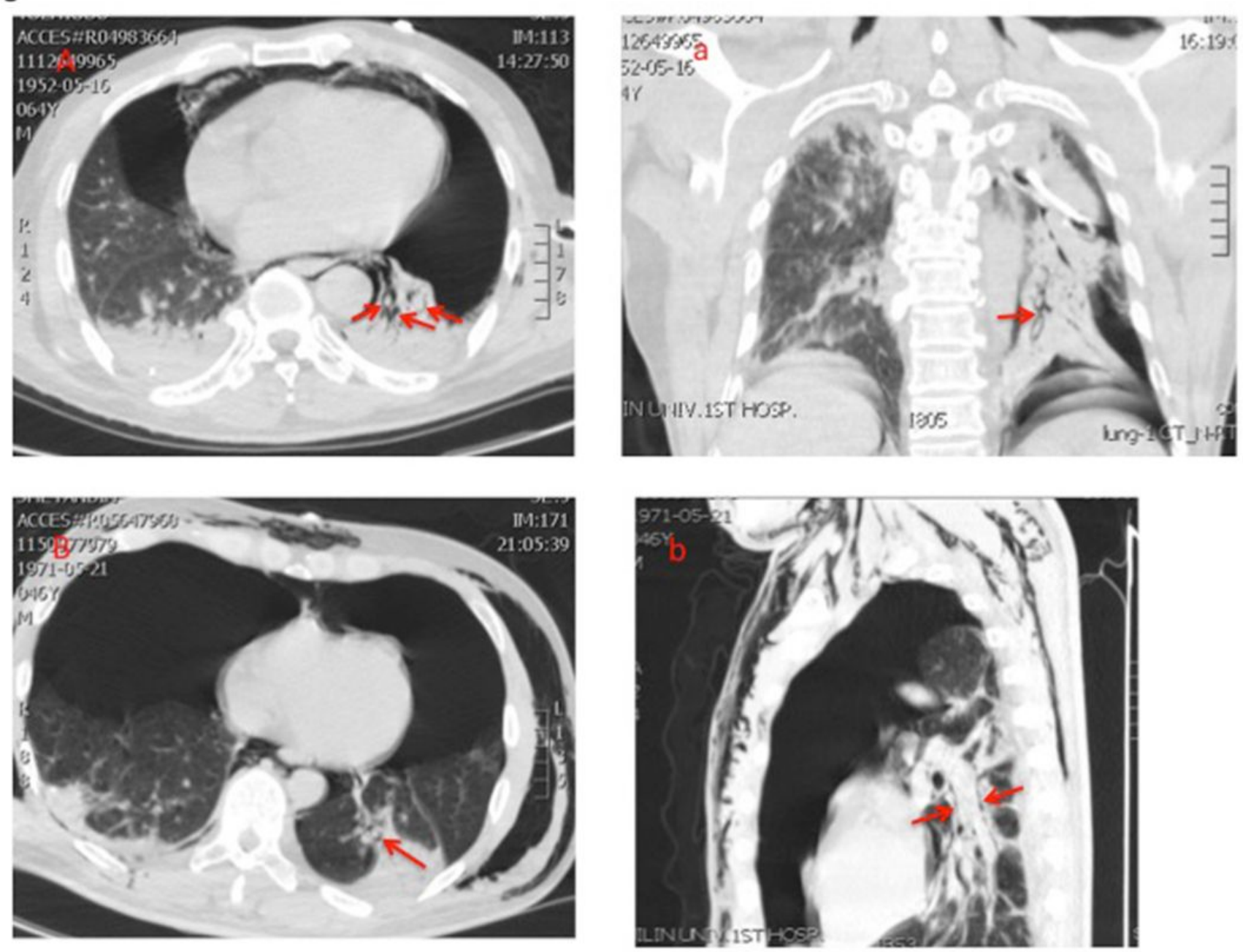

\section{Figure 3}

Chest CT scanning shows the Macklin effect. CT scanning demonstrates air collection along bronchovascular sheaths in the perihilar area. A and a present Macklin effect (arrows) of the patient 2. B and $b$ show the Macklin effect (arrows) in the patient 5 .

\section{Supplementary Files}

This is a list of supplementary files associated with this preprint. Click to download.

- supplement1.pdf 